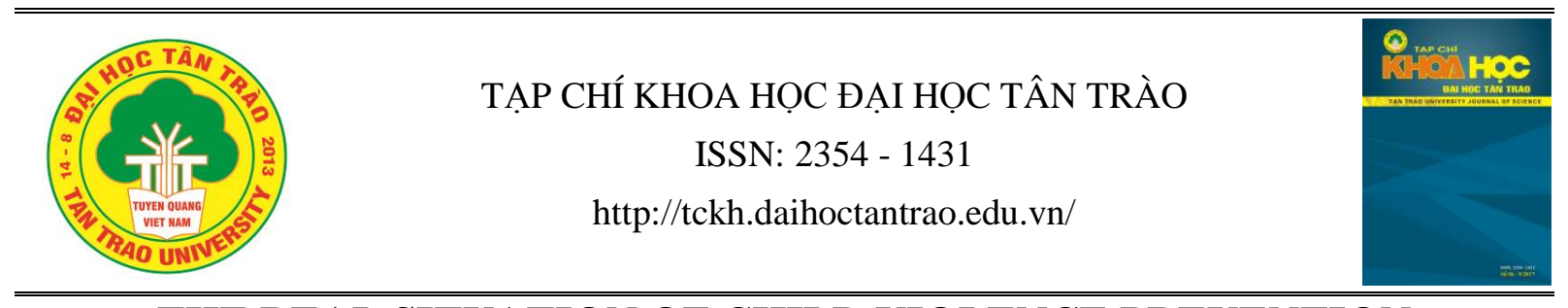

THE REAL SITUATION OF CHILD VIOLENCE PREVENTION AT THE PRESCHOOLS IN LONG XUYEN CITY, AN GIANG PROVINCE

Phan Thi Ngoc Nhanh ${ }^{1, *}$

${ }^{1}$ An Giang University, Vietnam

*Địa chi email: ptnnhanh@agu.edu.vn

http://doi.org/10.51453/2354-1431/2021/634

\section{Article info}

Recieved: $30 / 7 / 2021$

Accepted: 05/9/2021

\section{Keywords:}

The real situation, the violence, the child, preschool teachers, Long

Xuyen city, An Giang province.

\begin{abstract}
This study surveyed 58 preschool teachers working in Long Xuyen City, An Giang province to find out the current situation of violence and to offer solutions to prevent child violence. The research results show that: Child violence in preschools is mainly in physical and psychological forms with the rate of $37.7 \%$, the reason is the hard working and psychology recognizing your child's differences. On that basis, the study proposed two groups of solutions to prevent child violence. In particular, the increasing of teachers' ethical education and practical career experience for students of pedagogy combined with other solutions in preschool is basic.
\end{abstract}


TẠP CHÍ KHOA HỌC ĐẠI HỌC TÂN TRÀO

ISSN: $2354-1431$

http://tckh.daihoctantrao.edu.vn/

\title{
THỰC TRẠNG PHÒNG CHỐNG BẠO HÀNH TRẺ EM Ở CÁC TRƯờNG MẦM NON TẠI THÀNH PHỐ LONG XUYÊN, TỈNH AN GIANG
}

\author{
Phan Thị Ngoc Nhanh ${ }^{1, *}$ \\ ${ }^{1}$ Truò̀ng Đại học An Giang, Việt Nam \\ *Địa chỉemail: ptnnhanh@agu.edu.vn \\ http://doi.org/10.51453/2354-1431/2021/634
}

\section{Thông tin bài viết}

Ngày nhận bài: 30/07/2021

Ngày duyệt đăng: 05/9/2021

\section{Từ khóa:}

Thực trạng, bạo hành, trẻ em, giáo viên mầm non, Thành phố Long Xuyên, tỉnh An

Giang.

\section{Tóm tắt}

Nghiên cứu này đã khảo sát 58 giáo viên mầm non đang công tác tại Thành phố Long Xuyên, tỉnh An Giang để tìm hiểu thực trạng bạo hành; từ đó đề xuất một số giải pháp phòng chống bạo hành trẻ em. Kết quả nghiên cứu cho thấy: Bạo hành trẻ xảy ra ở các trường mầm non chủ yếu ở hai dạng thể chất và tâm lý với tỉ lệ $37,7 \%$, nguyên nhân là do sự vất vả trong công việc và tâm lý chưa chấp nhận những sự khác biệt của trẻ. Trên cơ sở đó, nghiên cứu đã đề xuất hai nhóm giải pháp nhằm góp phần phòng chống bạo hành trẻ em. Trong đó, việc tăng cường giáo dục đạo đức nhà giáo và trải nghiêm thự tế nghề nghiệp cho sinh viên ngành sư phạm kết hợp với các biện pháp khác ở trường mầm non được xem là giải pháp cơ bản.

\section{Mở đầu}

Trẻ em là hạnh phúc của gia đình, là tương lai của đất nước. Lợi ích của trẻ em cần phải được đặt lên hàng đầu bởi vì trẻ là chủ nhân tương lai của đất nước. Vì vậy, Đảng và Nhà nước ta đã dành nhiều sự quan tâm đặc biệt đến trẻ em, coi đây là trách nhiệm to lớn của đất nước. Tuy nhiên, tình hình bạo hành trẻ em đã trở thành vấn đề đáng lên án làm cho xã hội phải suy ngẫm. Theo khảo sát của Tổng cục thống kê thì có gần $80 \%$ trẻ em Việt Nam từ $2-14$ tuổi bị trừng phạt bằng bạo lực [9]. Trong thời gian qua, hàng loạt vụ bạo hành trẻ em ở các cơ sở Giáo dục mầm non liên tục được phát hiện và đưa ra ánh sáng. Điển hình là vụ bạo hành trẻ ở cơ sở mầm non tư thục Mầm xanh - Quận 12 - Thành phố Hồ Chí Minh đã gây xôn xao dư luận trong thời gian qua trên các phương tiện truyền thông [1] và hàng trăm vụ bạo hành khác.

Giáo dục mầm non có một vị trí đặc biệt quan trọng trong việc đặt nền móng cho sự hình thành nhân cách của trẻ em. Những giáo viên mầm non là người "ươm mầm xanh tương lai”; quan điểm, tư tưởng và cách ứng xử của giáo viên mầm non sẽ ảnh hưởng rất lớn đến tâm lý và nhân cách của trẻ. Bạo hành trẻ mầm non không chỉ ảnh hưởng đến sự phát triển thể chất, gây hậu quả nghiêm trọng trong quá trình phát triển tâm lý của trẻ mà còn ảnh hưởng nghiêm trọng đến uy tín và danh dự của ngành nghề Giáo dục mầm non nói riêng và nghề sư phạm nói chung. Trước tình hình đó, việc tìm ra các giải pháp góp phần ngăn chặn bạo hành trẻ mầm non là hết sức cấp thiết. 


\section{Nội dung nghiên cứu}

\subsection{Các khái niệm co bản}

\subsubsection{Khái niệm trẻ em}

Theo định nghĩa của từ điển tiếng Việt, trẻ em thuộc các lứa tuổi thiếu niên, nhi đồng, gọi tắt là thiếu nhi, có độ tuổi từ bốn - năm đến mười bốn mười lăm [6]. Trong các công ước quốc tế về liên quan việc bảo vệ quyền con người, quyền của phụ nữ và trẻ em thì trẻ em là người dưới 18 tuổi. Còn ở Điều 1 - Luật trẻ em ban hành năm 2016 của Quốc hội, trẻ em là người dưới 16 tuổi. Về mặt sinh học, trẻ em là những con người ở giữa giai đoạn sơ sinh và tuổi dậy thì [2].

Như vậy, trẻ em là từ nói chung biểu thị cho một đứa trẻ, một người chưa trưởng thành; tâm sinh lý còn non nớt, chưa hoàn thiện, nhận thức xã hội và hành vi chưa chín chắn.

\subsubsection{Khái niệm trẻ em trong trưòng mầm non}

Theo Luật Giáo dục Việt Nam năm 2019 thì trẻ em trong trường mầm non có độ tuổi từ ba tháng đến sáu tuổi; trong đó lứa tuổi nhà trẻ là từ ba tháng đến 3 tuổi, lứa tuổi mẫu giáo là từ ba tuổi đến sáu tuổi [3]. Trẻ em trong trường mầm non là lứa tuổi bắt đầu hình thành nhân cách, lĩnh hội tri thức, phát triển trí tuệ, hình thành phẩm chất đạo đức con người.

\subsubsection{Khái niệm bạo hành trẻ em}

Theo Tổ chức Y tế Thế giới, bạo hành trẻ em là tất cả những hành vi đối xử tệ bạc về thể chất hay tinh thần, xâm hại tình dục, lợi dụng hay bỏ bê, dẫn đến nguy hại hay khả năng nguy hại đối với sức khỏe, nhân phẩm, hay sự phát triển của trẻ [5].

Bạo hành trẻ em thể hiện ở bốn dạng: bạo hành thể chất, bạo hành tâm lý, bạo hành tình dục, bỏ bê, lạm dụng. Tuy nhiên bạo hành thể chất và bạo hành tâm lý là phổ biến nhất. Bạo hành thể chất bao gồm những hành động như: đánh đập (đấm, đá, tát, nắm tóc, dùng roi, ...), bóp cổ hoặc lắc trẻ thô bạo, ném hoặc xô đẩy trẻ, làm phỏng và tất cả các hành vi có khả năng gây thương tích về mặt thể xác khác. Bạo hành tâm lý là những hành vi gây nguy hại đến sự phát triển tinh thần và kỹ năng xã hội của trẻ, để lại chấn thương tâm lý đáng kể cho trẻ. Bạo hành tâm lý trẻ em có thể là những hành động từ chối, bỏ bê trẻ bằng những lời nói hoặc cử chỉ, thái độ như: Nói với trẻ rằng "Không ai yêu thương trẻ"; không đáp trả tình yêu thương; ngắt lời trẻ trong các cuộc đối thoại; mặc kệ cảm xúc của trẻ, chỉ trích, nhục mạ trẻ; đập phá đồ, la hét vào mặt trẻ; đỗ thừa trẻ; đe dọa hoặc phạt trẻ bằng hình thức bỏ rơi, đánh đập; khiến cho trẻ mất đi niềm tin vào chính mình; ...

\subsubsection{Tác hại của bạo hành đối với trẻ mầm non}

Xét về góc độ tâm lý, trẻ bị bạo hành hoặc chứng kiến bạo hành sẽ bị kích động tâm lý, tỏ ra giận dữ, gắt gỏng, buồn chán, sợ bị bỏ rơi và để lại trong trẻ những thù hận, căm giận; khi trẻ đủ sức phản kháng, trẻ sẽ vùng dậy, bản năng phòng vệ của con người dâng cao, lúc đó trẻ sẽ không còn quan tâm đến đạo lí, quy tắc mà có những hành động hư hỏng, dễ giận dỗi, dễ rơi vào stress, ám ảnh. Một số khác sẽ có hành động thu mình, nhút nhát, lo sợ, dễ phục tùng vô điều kiện, lẩn tránh người khác, tỏ ra chán đời, kém thông minh, chậm chạp. Việc trẻ bị bạo hành trong thời gian dài sẽ để lại những cú sốc tâm lý ảnh hưởng nặng nề về sau, ảnh hưởng đến nhiều mặt như sự phát triển nhân cách, hành vi; khi trưởng thành sẽ có thể lặp lại hành vi bạo hành đối với người khác hoặc những hành vi phạm pháp [4].

Ở góc độ sinh lý, hành vi bạo hành ảnh hưởng đến sức khoẻ và sự phát triển thể chất của trẻ, làm cản trở sự phát triển thể chất ở trẻ. Trẻ bị bạo hành thường bị thương tích về thể chất dễ dàng nhận thấy như: vết thương bầm tím, rách da, chảy máu hoặc một số chấn thương bên trong não, phổi, lá lách, gan,... Những tổn thương này nếu không được phát hiện và cấp cứu kịp thời có thể khiến trẻ bị tử vong. Đôi khi, trẻ có thể gặp vấn đề về sức khỏe như bệnh về tâm lý thần kinh, thậm chí là động kinh.

\subsection{Thục trang bao hành trẻ em ở các truò̀ng} mầm non

\subsubsection{Phwơng pháp nghiên cúu}

Khảo sát cắt ngang bằng phiếu hỏi 58 giáo viên mầm non đang công tác tại 5 trường nhà trẻ, mẫu giáo trên địa bàn thành phố Long Xuyên, tỉnh An Giang: nhà trẻ Măng Non, nhà trẻ Tuổi Thơ, mẫu giáo Hoa Sen, mẫu giáo Hoàng Oanh, mẫu giáo Hướng Dương để tìm hiểu thực trạng, nguyên nhân bạo hành; làm cơ sở cho việc đề xuất các giải pháp phòng chống bạo hành trẻ em.

Số liệu khảo sát thu về được phân tích định lượng bằng phần mềm Microsoft Excel. Các số liệu được phân tích bao gồm: tỉ lệ phần trăm, giá trị trung bình.

\subsubsection{Một số nét khái quát về số luợng khảo sát}


P.T.N.Nhanh/No.23_Oct 2021|p.31-39

Bảng 1: Đặc điểm giáo viên mầm non tham gia khảo sát

\begin{tabular}{|l|l|}
\hline Tuổi đời bình quân & 31,6 tuổi \\
\hline Quan điểm giáo dục & Không đòn roi \\
\hline Yêu trẻ & $100 \%$ giáo viên có lòng yêu trẻ \\
\hline Khả năng kiềm chế & $85 \%$ có khả năng kiểm soát được cảm xúc của bản thân \\
\hline Nhận thức về các dạng bạo hành & $\begin{array}{l}17 \% \text { giáo viên mầm non không nhận dạng được các hành động bạo } \\
\text { hành thể chất và tâm lý }\end{array}$ \\
\hline Hành động thường dùng với trẻ nghịch & Nhắc nhở nhẹ nhàng \\
\hline
\end{tabular}

Qua số liệu khảo sát, các giáo viên mầm non ở Thành phố Long Xuyên, tỉnh An Giang với tuổi đời bình quân còn trẻ, quan điểm giáo dục "Không đòn roi” đã tự nhận xét rằng mình có tình yêu thương đối với trẻ nhỏ, có kỹ năng kiềm chế tốt và cách ứng xử nhẹ nhàng với trẻ.

2.2.3. Các dạng bạo hành ở trường mầm non

Bảng 2: Các dạng bạo hành và mức độ bạo hành ở trường mầm non

\begin{tabular}{|l|c|c|c|c|c|}
\hline \multirow{2}{*}{ Các dạng bạo hành } & \multicolumn{2}{|c|}{ Tỉ lệ sử dụng (\%) } & \multicolumn{3}{|c|}{ Mức độ sử dụng (\%) } \\
\cline { 2 - 6 } & Có & Không & Hiếm khi & Thỉnh thoảng & Thường xuyên \\
\hline Bạo hành thể chất & $\mathbf{3 7 , 9}$ & $\mathbf{6 2 , 1}$ & $\mathbf{6 8 , 1}$ & $\mathbf{0 , 0}$ & $\mathbf{3 1 , 9}$ \\
\hline Đánh đập trẻ & 39,7 & 60,3 & 69,6 & 0,0 & 30,4 \\
\hline Ném, xô đẩy trẻ & 36,2 & 63,8 & 66,7 & 0,0 & 33,3 \\
\hline Bạo hành tâm lý & $\mathbf{3 7 , 5}$ & $\mathbf{6 2 , 5}$ & $\mathbf{6 5 , 6}$ & $\mathbf{9 , 2}$ & $\mathbf{2 5 , 1}$ \\
\hline La mắng, chỉ trích trẻ & 44,8 & 55,2 & 42,3 & 19,2 & 38,5 \\
\hline Từ chối, bỏ bê ý muốn của trẻ & 41,4 & 58,6 & 56,0 & 24,0 & 20,0 \\
\hline Bỏ rơi, mặc kệ trẻ & 41,4 & 58,6 & 66,7 & 12,5 & 20,8 \\
\hline Đe dọa trẻ & 39,7 & 60,3 & 69,6 & 8,7 & 21,7 \\
\hline Cô lập trẻ khỏi bạn bè & 36,2 & 63,8 & 76,2 & 9,5 & 14,3 \\
\hline Đập phá, la, thét vào mặt trẻ & 32,8 & 67,2 & 73,7 & 0,0 & 26,3 \\
\hline Không cho trẻ ăn uống & 32,8 & 67,2 & 68,4 & 0,0 & 31,6 \\
\hline Không làm vệ sinh cho trẻ & 31,0 & 69,0 & 72,2 & 0,0 & 27,8 \\
\hline Trung bình chung & $\mathbf{3 7 , 7}$ & $\mathbf{6 2 , 3}$ & $\mathbf{6 6 , 9}$ & $\mathbf{4 , 6}$ & \\
\hline
\end{tabular}

Qua số liệu trong bảng 2 ta thấy, có khoảng 37,7\% giáo viên mầm non có sử dụng các hành động bạo hành trẻ; tuy nhiên các giáo viên chỉ sử dụng khi thật cần thiết. Với 26 lượt lựa chọn, la mắng trẻ là hành động mà giáo viên sử dụng nhiều nhất $(44,8 \%)$ và mức độ sử dụng thường xuyên cao nhất $(38,5 \%)$ trong số các hành động được khảo sát. Các hành động xử phạt này thường được áp dụng khi trẻ nghịch ngợm trong các giờ ăn, hoạt động học, hoạt động góc, ... 
2.2.4. Nguyên nhân của các vụ bạo hành

\subsubsection{Nguyên nhân khách quan}

Bảng 3: Nguyên nhân khách quan của bạo hành trẻ ở trường mầm non

\begin{tabular}{|l|c|c|c|}
\hline Các nguyên nhân & $\begin{array}{c}\text { Số lượt lựa } \\
\text { chọn }\end{array}$ & Tỉ lệ \% & $\begin{array}{c}\text { Mức độ tác } \\
\text { động }\end{array}$ \\
\hline Công việc quá tải, vất vả, thời gian kéo dài, trách nhiệm cao, $\ldots$ & 47 & 81,0 & 3,71 \\
\hline Trẻ hiếu động, kém tập trung, không ngủ, không ăn, ... & 15 & 25,9 & 3,33 \\
\hline $\begin{array}{l}\text { Áp lực từ phía phụ huynh (trẻ phải bụ bẫm, khoẻ mạnh, lành lặn, } \\
\ldots\end{array}$ & 10 & 17,2 & 3,31 \\
\hline $\begin{array}{l}\text { Nguyên nhân khác: trẻ đông, giáo viên ít được quan tâm về tinh } \\
\text { thần, ... }\end{array}$ & 7 & 12,1 & 4,06 \\
\hline Nhu cầu từ gia đình của giáo viên (chăm lo chu toàn cho gia đình) & 5 & 8,6 & 3,35 \\
\hline $\begin{array}{l}\text { Lương thấp } \\
\text { Áp lực của ban giám hiệu về tỉ lệ trẻ đến lớp, số lượng trẻ tăng } \\
\text { cân, ... }\end{array}$ & 1 & 1,7 & 3,40 \\
\hline
\end{tabular}

Bảng 3 cho thấy, tất cả các nguyên nhân khách quan được khảo sát đều tác động khá lớn đến hành vi bạo hành trẻ, trong đó các nguyên nhân khác: trẻ đông, giáo viên ít được quan tâm về tinh thần có mức độ tác động lớn nhất đến giáo viên. Trong số các nguyên nhân khách quan được khảo sát ở trên thì áp lực từ công việc chăm sóc, giáo dục trẻ là nguyên nhân cơ bản nhất dẫn đến những hành động bạo hành trẻ xét về tỉ lệ \% cũng như về mức độ tác động. Ngoài ra, các yếu tố như: giáo viên không kiềm chế được xúc cảm của bản thân; gia đình trẻ kỳ vọng quá nhiều về trẻ và đặt quá nhiều yêu cầu đối với giáo viên; việc đưa đón con cái, chăm sóc nhà cửa và gia đình; công tác kiểm tra, dự giờ của ban giám hiệu, giáo viên không được quan tâm về tinh thần, trẻ đông, nội quy trường học còn lỏng lẻo, ... cũng góp phần tạo ra bạo hành. Trong đó, số lượng trẻ quá đông, giáo viên ít được chăm lo về mặt tinh thần,...có tác động lớn đến hành động bạo hành trẻ. Nghiên cứu của Nguyễn Thị Phú Quý, Bùi Thế Bảo về nguyên nhân bạo hành trẻ mầm non tư thục ở thành phố Hồ Chí Minh năm 2019 cũng đã chỉ ra 3 yếu tố khách quan cho là có tác động nhiêuu nhất đến các hành vi bạo hành là áp lực từ phía cha mẹ, người quản lí về thể trạng của trẻ; áp lực từ xã hội (những đánh giá của xã hội về người chăm sóc trẻ khi phát hiện các vụ tai nạn của trẻ ở trường mầm non) và khối lượng công việc quá nhiều, với tỉ lệ lựa chọn trên $96 \%$ [8].

Các giáo viên mầm non đã chịu nhiều áp lực từ công việc chuyên môn, về thời gian lao động; đặc biệt là ở nhà trẻ, công tác chăm sóc trẻ đòi hỏi nhiều thời gian, công sức và tình yêu. giáo viên mầm non thường làm việc với hàng chục trẻ, đến tối về nhà lại phải lo cho gia đình, con cái của họ. Công việc áp lực, đồng lương lại thấp, lâu ngày dẫn đến sự căng thẳng cũng là có thể dẫn đến bạo hành. Như vậy vấn đề cần thiết là giảm tải áp lực tinh thần, bố trí số lượng trẻ/ cô hợp lý và giảm bớt công việc hồ sơ sổ sách, lao động chân tay không cần thiết khác cho giáo viên để các cô có thể dành toàn thời gian và tâm ý cho công việc chăm sóc, giáo dục trẻ.

2.2.4.2. Nguyên nhân chủ quan

Bảng 4: Nguyên nhân chủ quan của bạo hành trẻ ở trường mầm non

\begin{tabular}{|l|c|c|c|}
\hline Các nguyên nhân & Số lượt lựa chọn & Tỉ lệ \% & Mức độ tác động \\
\hline Chưa chấp nhận những đặc điểm khác biệt của trẻ & 35 & 60,3 & 2,46 \\
\hline Dễ căng thẳng & 30 & 51,7 & 2,42 \\
\hline Chưa thật sự yêu nghề & 22 & 37,9 & 4,40 \\
\hline Chưa đủ kiến thức về nhu cầu tâm lý trẻ & 18 & 31,0 & 3,71 \\
\hline
\end{tabular}


P.T.N.Nhanh/No.23_Oct 2021|p.31-39

\begin{tabular}{|l|c|c|c|}
\hline Các nguyên nhân & Số lượt lựa chọn & Tỉ lệ \% & Mức độ tác động \\
\hline Chưa đủ kiến thức về nhu cầu phát triển thế chất của trẻ & 15 & 25,9 & 2,38 \\
\hline Nghĩ rằng la mắng sẽ làm trẻ ngoan hơn & 11 & 19,0 & 2,42 \\
\hline Chưa biết cách xử lý tình huống sư phạm & 10 & 17,2 & 2,35 \\
\hline Không đủ kiên nhẫn, kém kiềm chế cảm xúc & 9 & 15,5 & 3,85 \\
\hline Nghĩ rằng dùng hình phạt sẽ dễ dạy trẻ hơn & 4 & 6,9 & 2,70 \\
\hline
\end{tabular}

Tất cả các nguyên nhân chủ quan được khảo sát đều có ảnh hưởng đến hành vi bạo hành trẻ, trong đó việc giáo viên chưa chấp nhận trẻ là một cá thể khác biệt về mặt tình cảm, đặc điểm tâm sinh lý được đề cập nhiều nhất; tuy nhiên mức độ ảnh hưởng không lớn. Việc này khiến giáo viên khó có thể bao dung cho những hành động không mong đợi từ trẻ. Đa số giáo viên mong muốn trẻ ngoan ngoãn, biết vâng lời và thực hiện những gì mà giáo viên cho là tốt với trẻ mà quên rằng trẻ em có những đực điểm tâm lý riêng, khác hẳn với mình. Vì thế, việc tìm hiểu, nắm bắt xu hướng phát triển thể chất, tâm lý của trẻ và thừa nhận những đặc

điểm đó là vấn đề quan trọng để giáo viên mầm non có thể làm bạn với trẻ trong quá trình giáo dục.

Việc giáo viên chưa yêu nghề, mến trẻ là nguyên nhân có tác động rất lớn đến hành vi bạo hành trẻ. Ngoài ra, việc giáo viên chưa đủ kiến thức về nhu cầu tâm lý của trẻ, không đủ kiên nhẫn và kém kiềm chế cảm xúc bản thân cũng góp phần khá lớn vào việc tạo ra bạo hành. Trẻ em lứa tuổi mầm non là một cá thể khác biệt với người lớn cả về sinh lý lẫn tâm lý. Chẳng hạn, trẻ chưa tự thực hiện các hoạt động vệ sinh cá nhân cần giáo viên phải kiên nhẫn hướng dẫn hoặc trẻ biết làm nhưng vì tâm lý muốn được quan tâm, yêu thương nên trẻ thường nhõng nhẽo, đòi hỏi cô giáo thực hiện thay.

Bảng 5: Mức độ cần thiết của các biện pháp phòng chống bạo hành trẻ em

\begin{tabular}{|c|c|c|}
\hline Biện pháp & Mức độ cần thiết & Thư bậc \\
\hline Rèn luyện lòng yêu trẻ & 4,88 & 1 \\
\hline Giảm tải công việc & 4,86 & 2 \\
\hline Điều chỉnh chế độ chính sách & 4,83 & \multirow{2}{*}{3} \\
\hline Giảm số lượng trẻ/ lớp & 4,83 & \\
\hline Rèn luyện tính kiên nhẫn & 4,79 & \multirow{2}{*}{4} \\
\hline Học cách kiềm chế cảm xúc & 4,79 & \\
\hline Rèn luyện lòng yêu nghề & 4,74 & 5 \\
\hline Nắm vững đặc điểm tâm lý của trẻ & 4,67 & 6 \\
\hline Tăng cường giáo dục đạo đức nhà giáo cho sinh viên & 4,36 & 7 \\
\hline Lắp camera giám sát & 3,69 & \multirow{2}{*}{8} \\
\hline Cho phụ huynh tham gia lớp học định kì & 3,69 & \\
\hline
\end{tabular}

Qua khảo sát, có 9/11 biện pháp được đề xuất được cho là rất cần thiết trong việc giảm thiểu tình trạng bạo hành trẻ mầm non; trong đó ở thứ bậc cao nhất là giải pháp rèn luyện lòng yêu trẻ cho các giáo viên mầm non, cùng với đó là rèn luyện tính kiên nhẫn, khả năng kiềm chế cảm xúc của bản thân và lòng yêu nghề. Song, vẫn cần phải điều chỉnh một số yếu tố khách quan ảnh hưởng đến khả năng bạo hành là giảm tải khối lượng công việc trong ngày, giảm áp lực về số lượng trẻ trong lớp và có chế độ đãi ngộ tương xứng với khối lượng công việc của giáo viên mầm non. Kết quả khảo sát cho thấy, việc lắp camera giám sát và để phụ huynh tham gia vào quá trình học của trẻ để nắm bắt và phối hợp trong cách giáo dục trẻ cũng cần thiết trong việc hạn chế bạo hành.

Tóm lại, bạo hành trẻ em xảy ra ở trường mầm non do nhiều nguyên nhân khác nhau, có cả nguyên nhân chủ quan và khách quan đến từ nhiều phía. Dù là do đâu thì bạo hành trẻ em cũng là hành vi sai 
trái, vi phạm pháp luật về bảo vệ trẻ em, cần ngăn chặn và xử lý nghiêm minh để răn đe những người khác $[2,7]$. Do vậy, phòng chống bạo hành là vấn đề cần thực hiện ngay và tiến hành đồng bộ nhiều biện pháp mới mang lại hiệu quả thiết thực.

\subsection{Một số giải pháp phòng chống bạo hành}

\section{trẻ em}

2.3.1. Một số giải pháp cần thực hiện trong truò̀ng su phạm

Tăng cuờng các hoạt động giao lưu, trải nghiệm thưc tế ở trường mầm non nhằm tạo nhiều cơ hội cho sinh viên tiếp xúc với thực tế nghề nghiệp, với trẻ để hình thành, phát triển và củng cố lòng yêu nghề, mến trẻ. Đồng thời giúp sinh viên nhận thức rõ hơn về đặc điểm tâm sinh lý của trẻ mầm non, từ đó chấp nhận những khác biệt trong biểu hiện và hành động của trẻ so với bản thân mình. Để đạt được mục đích này, cần tiếp tục duy trì và nâng cao hiệu quả công tác trải nghiệm nghề nghiệp của sinh viên năm nhất; tổ chức thường xuyên hoạt động dự giờ minh hoạ, thực hành nghề nghiệp và ở trường mầm non; tích hợp nội dung học tập phục vụ cộng đồng phù hợp vào trong các học phần chuyên ngành Giáo dục mầm non.

Tăng cuờng giáo dục đạo đức nghề nghiệp, đạo đức nhà giáo cho sinh viên su phạm để góp phần hình thành một nhà giáo không chỉ có tài mà còn có tâm; một con người hoàn thiện đức, trí, thể, mỹ với những tư tưởng và niềm tin về những điều tốt đẹp thông qua các hoạt động sau: Tăng cường giáo dục phẩm chất chính trị cho sinh viên trong tuần lễ sinh hoạt công dân và trong các môn học, đặc biệt là nhóm môn học về khoa học chính trị; coi trọng hoạt động giáo dục đạo đức nghề nghiệp và sự tự tu dưỡng của bản thân sinh viên; lồng ghép giáo dục đạo đức nhà giáo mọi lúc, mọi nơi. Việc giáo dục phẩm chất đạo đức không chỉ gói gọn trong một môn học mà cần phải được thực hiện thường xuyên.

Tổ chức hiệu quả các hoạt động trải nghiệm tập thể có tính cộng đồng - xã họi để tạo cơ hội cho sinh viên được tham gia các hoạt động trải nghiệm thực tế, góp phần định hướng thẩm mỹ lành mạnh, giáo dục kỹ năng sống, hình thành và phát triển nhân cách tốt đẹp cho sinh viên. Khuyến khích, động viên sinh viên tham gia các hoạt động tình nguyện mang tính tập thể như: chiến dịch Mùa hè xanh, Xuân tình nguyện, Tiếp sức mùa thi, dạy chữ cho trẻ em nghèo,...; các cuộc thi văn nghệ thể thao, các ngày hội: Bảo vệ môi trường, Hội bánh dân gian Nam bộ, ... Thông qua các hoạt động đó, sinh viên có được những kỹ năng sống cần thiết cho hoạt động nghề nghiệp; đồng thời góp phần hình thành thế giới quan đúng đắn.

Lồng ghép, tích hợp nội dung, kiến thức pháp lý về quyền trẻ em, các hình thức bạo hành và phòng, chống bạo hành vào kế hoạch giáo dục của môn $h o ̣$ giúp sinh viên nhận biết đầy đủ về bạo hành, nhận diện rõ các hành vi bạo hành và những quy định của pháp luật về phòng chống bạo hành, bạo lực học đường; qua đó các em sẽ có nhận thức toàn diện về các vấn đề có liên quan đến bạo hành, biết về cái sai, cái vi phạm mà tránh né.

2.3.2. Một số giải pháp cần thực hiện trong trừ̀ng mầm non

Lắp camera giám sát. Với mục đích quản lý an ninh, kiểm tra giám sát hoạt động của giáo viên, của trẻ từ xa; hầu hết các trường nhà trẻ, mẫu giáo trên địa bàn Thành phố Long Xuyên, tỉnh An Giang đã lắp camera ở khu vực hành lang, khu vui chơi của trẻ; một số trường còn lắp ngay trong phòng học. Nhờ con mắt thứ 3 này mà các hành động bột phát của giáo viên mầm non cũng được hạn chế đáng kể. Xét về phương diện tâm lý học, nếu biết có người thứ 3 đang quan sát mình thì những cảm xúc của bản thân sẽ được kiềm chế tốt hơn, do vậy hành động xảy ra sẽ nhẹ nhàng và hợp lý hơn.

Triển khai các mô hình phối hợp gia đình - nhà truò̀ng - cộng đồng trong chăm sóc, giáo dục trẻ. Giáo dục gia đình có ảnh hưởng sớm và rất lớn đối với trẻ. Giáo dục con cái trong gia đình không phải chỉ là việc riêng tư của bố mẹ, mà còn là trách nhiệm đạo đức và nghĩa vụ công dân của những người làm cha mẹ được xác định trong Hiến pháp, Luật Hôn nhân và gia đình, Luật Bảo vệ, chăm sóc và giáo dục trẻ em,... Để việc giáo dục trong gia đình có hiệu quả tốt, các bậc cha mẹ cần quan tâm xây dựng một gia đình đầy đủ, toàn vẹn, trong đó mọi thành viên có nghĩa vụ và trách nhiệm với nhau. Vì vậy việc hỗ trợ và tuyên truyền kiến thức, kỹ năng chăm sóc, giáo dục trẻ cho cha mẹ trẻ là điều hết sức cần thiết. Nhà trường cần phối hợp chặt chẽ với các tổ chức xã hội, cần phát huy vai trò là trung tâm văn hóa giáo dục của địa phương, tổ chức việc phổ biến các tri thức khoa học kĩ thuật, văn hóa xã hội, ... cho các bậc phụ huynh, giúp họ 
hiểu được đặc điểm trong đời sống, tâm sinh lý của trẻ hiện nay.

Giảm tải công việc và đura ra chế độ đãi ngộ tốt cho giáo viên mầm non. Là nghề vất vả, cả về thời gian và nội dung công việc; không chỉ dạy mà còn phải dỗ, chăm sóc trẻ từ miếng ăn, giấc ngủ, làm vệ sinh cho trẻ. Hơn nữa một tiết dạy cho trẻ mầm non cần đầu tư rất nhiều đồ dùng đồ chơi; trang trí lớp học cho đẹp, hấp dẫn, thú vị để các con yêu thích việc đến lớp, ... tất cả đều do giáo viên tự bỏ lương ra mà thực hiện. Tuy nhiên, ngoài mức lương theo hệ số và phụ cấp đứng lớp $35 \%$, giáo viên không có một khoản trợ cấp nào thêm nên đời sống rất chật vật, mọi chi tiêu trong nhà phải tính toán từng đồng, lúc cấp bách phải vay mượn; từ đó nhiều giáo viên mầm non cảm thấy vô cùng áp lực, muốn từ bỏ nghề. Do vậy, một là phải có chế độ đãi ngộ tốt sẽ giảm áp lực cho các giáo viên về cuộc sống, tạo điều kiện cho các cô yên tâm công tác và yêu nghề hơn; hai là phải điều chỉnh nội dung công việc để giảm áp lực cho giáo viên và để phù hợp với đồng lương mà giáo viên nhận được.

Bồi duỡng, nâng cao năng lục cán bộ quản lý, giáo viên, nhân viên, ngườ lao động trong công tác phòng chống bạo lục hoc đương ở co sở giáo duc. Trường mầm non và các tổ chức xã hội nên thường xuyên phối hợp tổ chức các hoạt động tuyên truyền về phòng chống bạo lực học đường; xây dựng các tài liệu hướng dẫn và tổ chức tập huấn, bồi dưỡng cho giáo viên mầm non tích hợp, lồng ghép nội dung giáo dục phòng chống bạo lực vào giáo dục tình cảm, kỹ năng xã hội; cấp quản lý và tổ trưởng chuyên môn cũng nên tích hợp nội dung này vào nội dung họp chuyên môn hàng tháng. Tích cực xây dựng môi trường giáo dục an toàn, lành mạnh, thân thiện; tổ chức tập huấn, bồi dưỡng, nâng cao năng lực cho cán bộ quản lý, giáo viên, nhân viên, người lao động về công tác phòng, chống bạo lực; thanh tra, kiểm tra, giám sát việc thực hiện công tác phòng, chống bạo hành tại cơ quan.

2.3.3. Một số giải pháp phòng chống bạo hành tù phía giáo viên mầm non

Thuờng xuyên tụ rèn luyện kỹ năng kiềm chế cảm xúc tiêu cực nhằm giúp giáo viên có thể làm chủ được cảm xúc của bản thân, giữ được bình tĩnh trước những hành động bản năng của trẻ, của những người xung quanh; từ đó có những phản ứng nhẹ nhàng, hợp lý trong quá trình chăm sóc, giáo dục trẻ; tránh trường hợp "Giận quá mất khôn” bằng cách: thực hành ức chế chậm trong mọi hoạt động sống; tham gia các khoá học ngắn hạn, hội thảo về kỹ năng mềm liên quan đến làm chủ, quản lý cảm xúc hoặc tự tham khảo các bài giảng online về cách giải toả cơn tức giận của các chuyên gia tâm lý uy tín.

Tăng cuờng bồi duõng lòng yêu nghề để có thêm động lực cho giáo viên mầm non gắn bó với nghề và chăm sóc trẻ chu đáo hơn. Nếu thực sự yêu nghề, giáo viên mầm non có thể vượt qua mọi áp lực, sự vất vả trong công việc một cách nhẹ nhàng mà không gây ra cảm xúc tiêu cực.

Bồi duỡng và phát triển tình yêu thuơng trẻ $n h o ̉$, bắt đầu từ việc thường xuyên trau dồi chuyên môn, kỹ năng nghề nghiệp, đặc biệt là nghiên cứu và nắm vững các đặc điểm tâm sinh lý của trẻ mầm non, chấp nhận rằng trẻ là một cá thể khác biệt, mỗi trẻ là một cá tính hoàn toàn khác nhau và khác với cô giáo để cảm thông cho sự hiếu động, thấu hiểu với những hành động quấy khóc không chịu ăn, ngủ, ... của trẻ; từ đó tránh những hành động bột phát, hành vi bạo hành.

\section{Kết luận}

Bạo hành trẻ em xảy ra ở các trường mầm non được khảo sát với tỉ lệ bình quân $37,7 \%$, các hành động bạo hành chủ yếu tập trung vào hai mảng thể chất và tâm lý. Tuy nhiên, các giáo viên cho rằng đó chỉ là hành động trừng phạt nhằm mục đích giúp trẻ ngoan hơn. Tình trạng bạo hành xảy ra một phần là do yếu tố khách quan đến từ sự vất vả trong công việc với tỉ lệ $81 \%$; một phần do tâm lý của giáo viên chưa chấp nhận được những sự khác biệt đến từ trẻ.

Phối hợp đồng bộ các giải pháp giáo dục ở trường sư phạm cho sinh viên ngành Giáo dục mầm non từ sớm, xuyên suốt trong quá trình học tập; và với nhiều giải pháp khác tại trường mầm non sẽ rất hữu ích cho công tác phòng chống bạo hành trẻ em nói riêng, bạo lực học đường nói chung. Trong đó, tăng cường các hoạt động trải nghiệm thực tế ở trường mầm non phối hợp giáo dục đạo đức nhà giáo mọi lúc mọi nơi và rèn luyện kỹ năng kiềm chế cảm xúc được xem là giải pháp thiết thực, chủ yếu nhằm hạn chế các nguyên nhân bạo hành xuất phát từ chủ quan; lắp camera, giảm việc và có chế độ đãi ngộ tốt cho giáo viên là các yếu tố cơ bản nhằm hạn chế các nguyên nhân khách quan gây ra bạo hành. 


\section{REFERENCES}

[1] Hai, T. (2017). Child abuse case at Green Kindergarten Ho Chi Minh City. https://vtv.vn.

[2] Congress. (2017). Children's Law. National Political Publishing House - The Truth.

[3] Congress. (2019.). Education Law. Law No. 43/2019/QH14.

[4] Huyen, T. T. (2006). Current status of domestic violence. Workshop on Social Issues in An Giang Province, 66.

[5] Kim, D. H. (2017). Child abuse - Definition, classification and behaviour. Access from https://www.whiteheathervn.com.
[6] Phe, H. (1992). Vietnamese Dictionary. Hong Duc Publishing House, 927.

[7] Phung, N. T. K., Lan, N. T. (2009). Overview of violence and legislation on prevention and control of violence against women and children. Jurisprudence Journal 2, 3.

[8] Quy, N. T. Q., Bao, B. T. (2019). Causes of violence against private preschool children in industrial zones and the vicinity of Ho Chi Minh City. Scientific Journal of Ho Chi Minh City University of Education, 16:141.

[9] VTV News. (2016). Suffering from violence and abuse of children. https://vtv.vn 